\title{
Enhancing Motivation and Engagement: A Top-Down Approach for the Design of a Learning Experience According to the S2P-LM
}

\author{
http://dx.doi.org/10.3991/ijet.v8i6.2955 \\ S.E. Bahji, Y. Lefdaoui and J. El Alami \\ Mohammed V Agdal University, Rabat, Morocco
}

\begin{abstract}
Demotivation and disengagement of students toward the formal learning curriculum, know an increasingly strong and even alarming proliferation.

In this paper, we try to deal with motivation and engagement of learners during learning process and learning experience within a formal context, by the adoption of a Top-Down approach through three levels of design: Macro, Meso, and Micro level.

The Macro Level tries to rely on a conceptual framework: the S2P Learning Model. The Meso Level is related to the design of the learning experience, by which we formalize the pedagogical scenario, the didactic tools, the pedagogical activities and roles: based on the Extended Blended Learning. Finally, the Micro Level stresses on the use of game mechanics and Gamification of activities and tools as a way to enhance the motivation and engagement of learners during the learning experience.
\end{abstract}

By these principles, we move gradually towards a new kind of teachers ("Integrators" \& "Facilitators"); and a new kind of learners ("Learnplayers").

Therefore, we try by this paper, to outline of the conceptual basis of our approach that must build the frame of validation by experimentation during the next steps of our research.

Index Terms-Blended Learning, Game-based Learning, Gamification, Motivation, S2P Learning Model.

\section{INTRODUCTION}

Learners nowadays become more and more disinterested in classroom, especially in undeveloped or developing countries.

In our context, we are face to different issues that make formal curriculums in tertiary education in concurrence according to several factors [5]: the expansion of the use of information technologies; the proliferation of Internet as a support of parallel learning; the learners that become more autonomous and more demanding; etc.

All those factors, and others, drive us to re-think the ways we adopt for instructional design in a way that allow us to increase loyalty to formal curriculums.

But, removing distraction from the classroom is an impossible mission! So, what motivates learners? How can keep their motivation and engagement? How to motivate learner to take action? How can we drive a motivating and engaging learning experience in the context of a developing Country? The debate still open.

Knowing that technologies transform education, teachers and students can set goals for their learning together, and work toward those. Also, teachers need to follow changes in society.

When the learner comes to the classroom with low intrinsic motivation, he could be motivated extrinsically by the teacher's choice of approaches and personal styles [30]. Therefore, the teacher's role in shaping the learner's motivation and attitudes towards learning is huge.

The purpose of the present paper is to present the outlines of our approach to deal with the issue of motivation and engagement during learning process, especially in a context of developing country.

Then, this paper will be organized according to two main sections:

In the first section, we will present the concepts of motivation \& engagement, and their importance in learning contexts.

In the second section, we will develop the outlines of our Top-Down Approach, to deal with motivation in Learning Context according to the layers of the S2P Learning Model.

\section{Motivation \& ENGAGEMENT IN LEARNING CONTEXT}

Learning is in a continued changing, at the same time learning is changing us. It becomes more difficult to master the motivation and engagement of learners during learning process, due to several factors: psychological, social, etc.

Z. Dörnyei and E. Ushioda have stated that demotivation "concerns various negative influences that cancel out existing motivation" [13]. In this context, the role of Information Technologies (IT) in motivating, engaging, and promoting creativity and innovation is huge. They can seem complicated, but they offer unparalleled opportunities, changing learning and learners.

\section{A. Motivation \& Engagement}

Motivation is defined in the Cambridge Academic Content Dictionary, as the "reason for doing something", "willingness to do something, or something that causes such willingness". 
According to M.L. Maehr and H.A. Meyer [19], Motivation is a theoretical construct used to explain the initiation, direction, intensity, persistence, and quality of behavior, especially goal-direction behavior.

This concept is used to refer to personality factors, social variables, thoughts, and beliefs that are presumed to underline the behaviors we observe [25]. And it can be described as an individual's personal investment in a particular activity [19].

At those terms, Motivation brings enthusiasm for doing something that we can assimilate to the significance and the reason of the action. Bringing then the target to enjoy, somehow, what he/she is doing.

At the other side, the Engagement (according to the Cambridge Learner's Dictionary) is seen as an arrangement "... to do something at a particular time". It refers to a commitment that converts the motivation into action.

\section{1) Types of motivation: Intrinsic vs. Extrinsic}

At this element, we can distinguish between two dimensions of motivation. The first one is related to The Intrinsic motivation, which is difficult to hold and to measure, and is related to the Cognitivism school.

The second dimension is related to the Extrinsic motivation. Supported by the Behaviorism school, where according to some stimulus we aim to develop such response, that we can measure and observe.

\section{2) Motivation as Drive and/or Goal}

In front to these two dimensions (intrinsic/extrinsic), different perceptions related to Motivation emerged. The first is the perspective that views Motivation as a drive, an internal state, need, or condition that impels individuals toward action [8].

The second perspective views Motivation as goals that entice individuals toward action. Arguing that all actions are given meaning, direction, and purpose by the goals that individuals seek out, and that the quality and intensity of behavior will change as these goals change [8].

Obviously, this drive/goal distinction is not entirely clear, based on the fact that "the same achievement behavior can often be construed as either satisfying a need or the result of pursuing a goal" [8]. Therefore, these two perceptions are, in our view, complementary.

\section{B. Motivation in the classroom: the learner in the centre of interest}

Nelson Mandela has said "Education is the most powerful weapon which you can use to change the world". We need it more than any time before, especially in developing or underdeveloped countries.

J.E. Brophy considered that learning is fun and exciting, at least when the curriculum is well matched to student's interests and abilities and teacher emphasizes hands-on activities, therefore "when you teach the right things the right way, motivation takes care of itself" [7].

But, due to several factors, keeping learners motivated and engaged during the learning experience is challenging issues nowadays.

To enhance motivation and engagement, the first step is to avoid demotivation. Then, four main types of demotivation factors were discovered in the learning context [30]:
- the teacher's personal relationship with students.

- the teacher's attitude towards the course or the material.

- style conflicts between teacher and students.

- and the nature of the classroom activities.

Demotivating factors can be divided into internal factors (i.e. reduced self-confidence, negative attitude toward the field studied, etc.), and external factors (i.e. teacher's personalities, learning environment, books and learning tools, etc.) [12].

When the teacher neglects the motivational aspects, he limits the learner's performance. So, it remains a key challenge for the teacher to give the meaning of what is administrated to the learner, to catch his interest and enhance motivation and engagement during learning activities. He has then to demonstrate the reason, facilitate the understanding of learning goals and vary didactic methodologies/approaches.

\section{TOP-DOWN APPROACH TO DEAL WITH MOTIVATION IN LARNING CONTEXT}

Universities, and tertiary education systems worldwide, are being transformed by new or changing practices, programs, policies, and agendas.

Nowadays tertiary education suffers from a kind of concurrence engaged by new technologies, new Medias, and new ways of access to knowledge which are everywhere.

Face to those changes, Moroccan Universities must devote more efforts to motivate and engage learners within the context of this changing, globalized and "unfair" concurrence.

By the motivation of learners, we try to stimulate their interest and to cause them to want to do tasks and to act in particular way. For this, we have to give them the reason, to make the sense, and to engage them into the learning curriculum. Then, cultivating motivation is crucial to the learner's success. And, to deal with this issue, especially within a developing country, we try to adopt a "TopDown approach" according to tree levels: Macro Level, Meso Level, and Micro Level (figures 1 and 2).

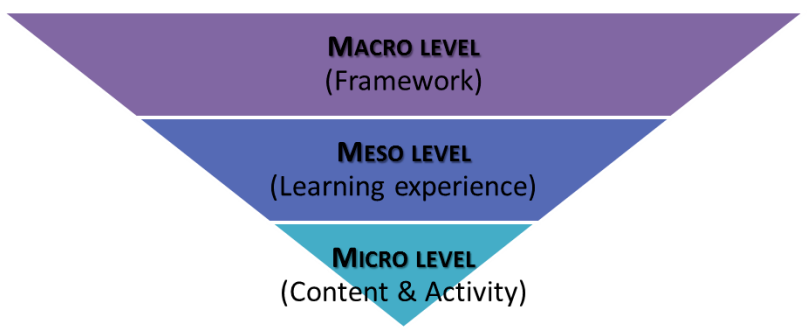

Figure 1. Top-Down approach

The Macro Level tries to rely on a conceptual framework: the $S 2 P$ Learning Model, as illustrated in previous works by S.E. Bahji et al. [3] [4] [5].

The Meso Level is related to the design of the learning experience, by which we formalize the pedagogical scenario, the didactic tools, the pedagogical activities and roles: based on the Extended Blended Learning.

Finally, the Micro Level stresses on the use of game mechanics and Gamification of activities and tools as a 
way to enhance the motivation and engagement of learners during the learning experience.

These are summarized in the following figure (figure 2).

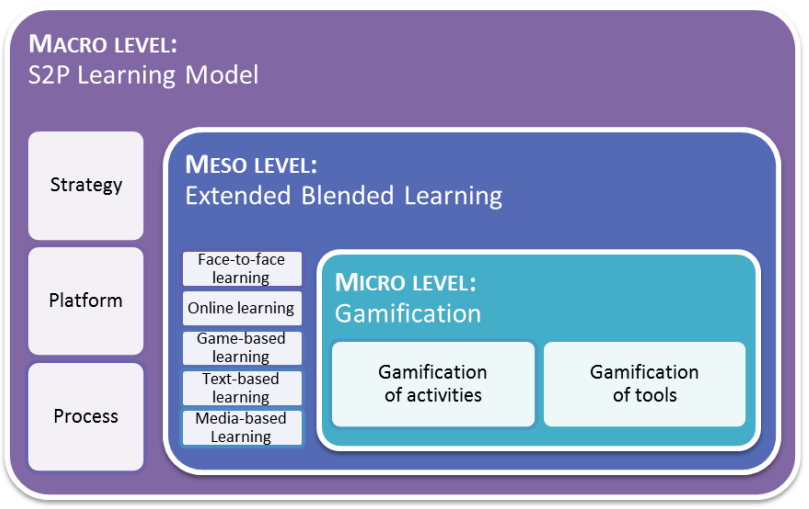

Figure 2. Tree levels of the Top-Down approach

\section{A. Marco Level: The S2P Framework}

The S2P Learning framework was previously developed by Bahji S.E. et al. [3] [4] [5].

It goes from the state that to understand any formal approach of learning, it would be appropriate to define a logical framework regulating the definition and implementation of any educational initiative [3]. And the S2P Learning Model was proposed for this purpose.

\section{1) S2P-LM: the characteristics}

This logical framework is designed through the definition of three complementary dimensions: a strategic dimension of reference (the Formal Learning Strategy), a technical dimension support (the Learning Platform), and a procedural dimension of acquisition (the Learning Process).

Learning Strategy: The Learning Strategy consists on defining a strategic view of formal learning. This definition requires the clarification of several priority elements such as: delimitation of the domains and fields; delimitation of the target population; definition of the appropriate pedagogical approach; definition of the pedagogical scenario; definition of the duration; etc.

Learning Platform: The Learning Platform concretizes the outlines of the "Formal Learning Strategy" as previously traced, and aims to support the achievement of the pedagogical objectives as defined within the Strategy [3].

Learning Process: Indeed, the Learning Process is clearly the element to support by the Learning Strategy and the Learning Platform, but at the same time, this Learning Process can contribute to the definition of the didactic tools by which we will define our Learning Platform, and also the refinement of Formal Learning Strategy [4]. Then, the Learning Process plays two roles:

- a source: a component of definition of the "Learning Strategy".

- a target: an element to be supported by the "Learning Platform".

These three components (Learning Strategy, Learning Platform, and Learning Process) are closely interconnected and interactive into a frame of relationship: "Definition"-“Support"-“Adjustment” [4].

This framework offers a platform of choice that affects entirety the curriculum and the learning experience. That's why it is considered as the Macro Level of our approach.

The holistic view of the framework S2P is presented in the figure 3 .

2) Why the $S 2 P-L M$ ?

Through the previous description, it should be noted that the focal point that characterizes the S2P-LM lies in its interest on the process rather than the content (Processbased rather than Content-based). It aims to foster a dynamic within the learner, arguing that the Content is no longer a problem. We can find it everywhere, and we can reach it at any time in a multiform way: Web, Cd-Dvd, $\mathrm{Tv}$, books, magazines, etc.

Also, the expansion of concepts like "Open Learning Resources" and "Open access content" lets us focus more on the Learning Processes, instead of focusing on the content, because this one is globalized nowadays.

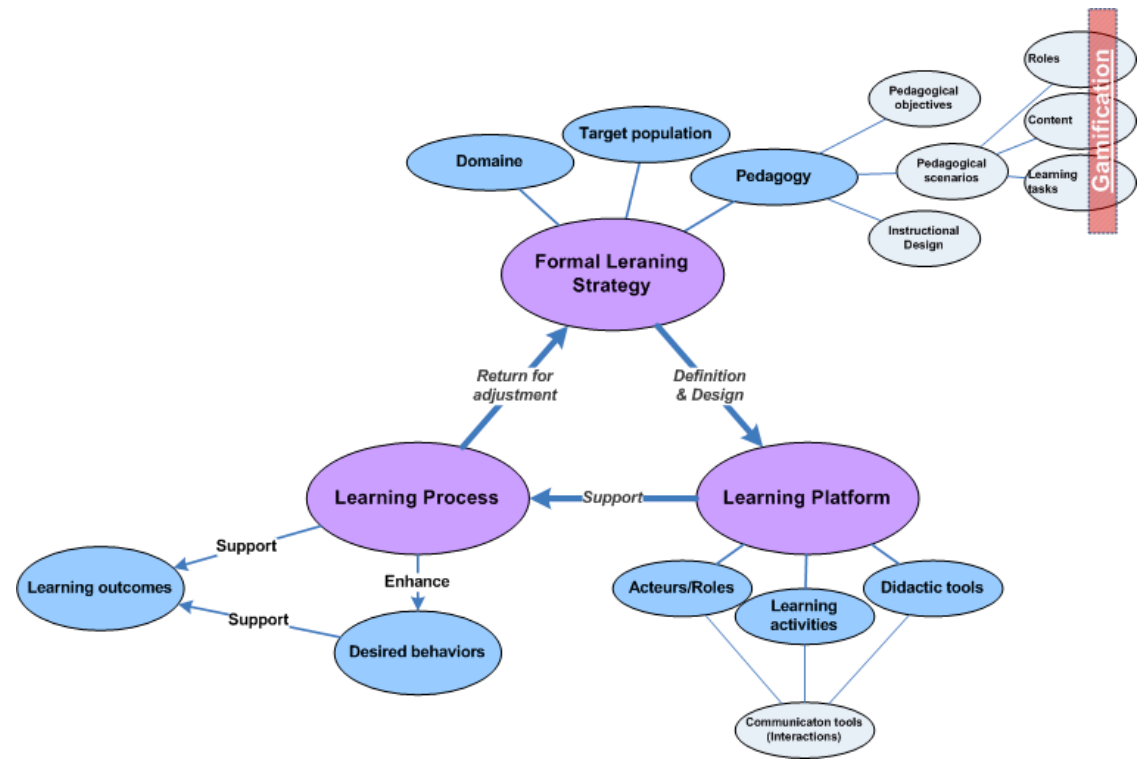

Figure 3. Macro Level: view of the S2P Learning Model 
In each Learning curriculum we can define the Learning Strategy and design the Learning Platform according to the Sub-Processes of Learning.

We start with the central question: What are the learning processes that we want to emphasize in order to reinforce the desired behavior among learners and to support achieving the learning outcomes?

We put the focus on four sub-processes, namely: Reflection process, Internalization process, Socialization process, and Decision-making process.

Then, regardless the balance between those subprocesses, each didactic tool can focus more or less on one or more aspects (figure 4).

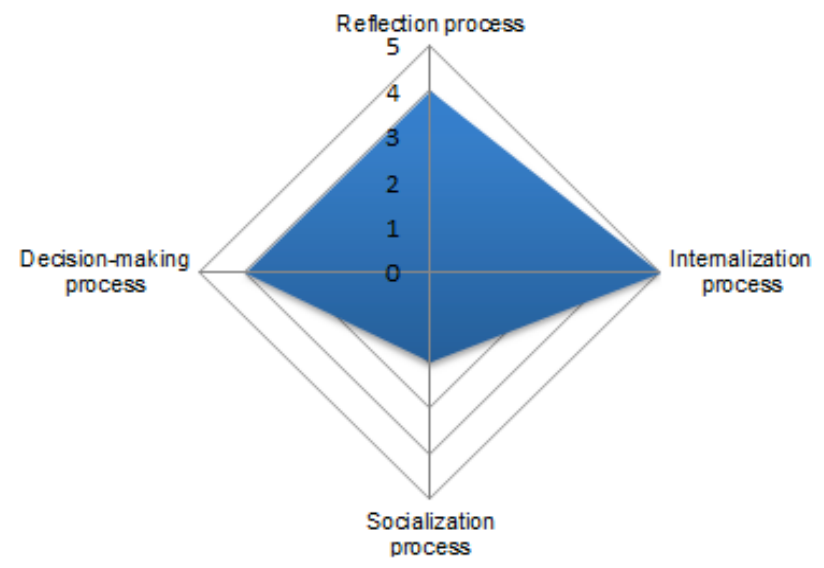

Figure 4. Balance between the Sub-Processes of Learning

At this context, each didactic tool, defined in the Learning Platform, must be analyzed according to Learning Sub-Processes that it supports and Cognitive Levels that it stresses.

Most important Cognitive Levels in the learning initiative are: remembering; understanding; applying; analyzing; evaluating; and creating (figure 4).

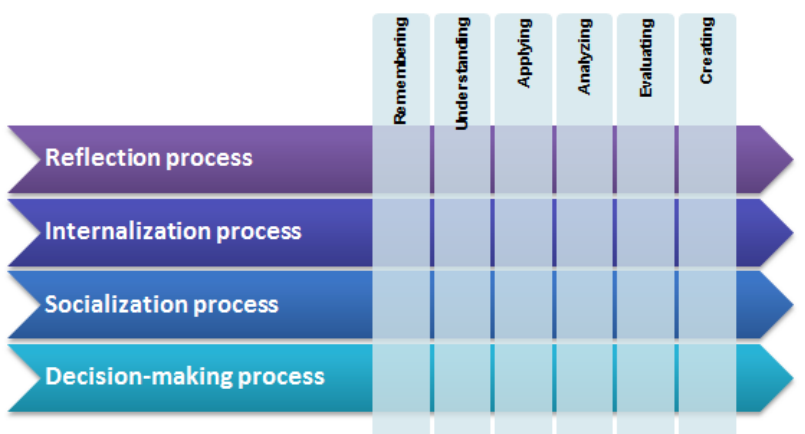

Figure 5. Sub-processes and cognitive levels in the Learning Process

At this point, we try to represent the sub-processes, occurring during the Learning Process, according to cognitive levels or "Cognitive aims" that they mobilize. Marking then a complementary distinction between cognitive levels across different learning sub-processes, we can have such a meta-representation of Processes/Cognitive goals represented in the figure 6.

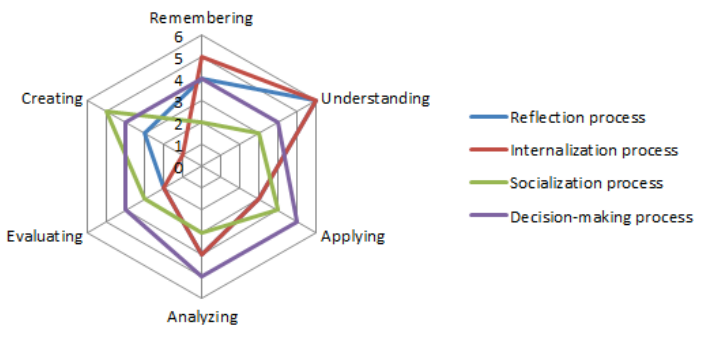

Figure 6. Meta-representation "Processes/Cognitive goals"

\section{B. Meso Level: Instructional design}

The Instructional design represents the layer between the Learning Strategy and the Learning Platform. It's the way of formalizing the strategy within a Learning System or Platform, as shown in following (figure 7). We stress, at this level, on the design of the Learning Platform that will support the learning experience.

As developed by S.E. Bahji et al. [4], combining several didactic tools and methods could enhance significantly the engagement of learners, especially the combination of Text-based Learning and Game-based Learning. Then, several factors related to the context of underdevelopment, leads us to adopt the MultilevelBlended Learning as the main vector of conception and design of the learning experience.

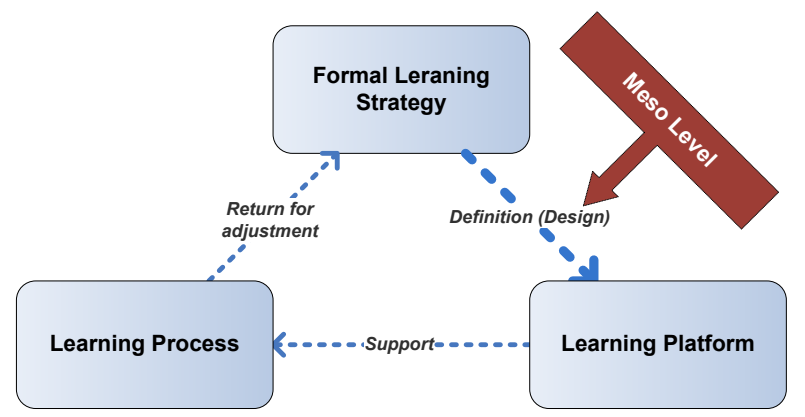

Figure 7. Meso Level

\section{1) Multilevel-Blended Learning: the Characteristics}

The concept "blended", "hybrid", "technologymediated instruction", and "mixed-mode instruction" are often used interchangeably in current research literature.

The Blended learning is education that combines faceto-face classroom methods with computer-mediated activities. According to its supporters, this creates a more integrated approach for both instructors and learners.

However, two philosophies characterize our line of research:

- The first philosophy refers to the logic of "mixed" based on several dimensions.

- The second philosophy refers to the logic of "integration" by following the new trends of globalized learning.

Then, we attribute to Blended Learning multiple dimensions (figure 8), namely:

- Face-to-face vs. Online.

- Text-based Learning vs. Game-based Learning and Media-based Learning.

- Serious games vs. Gamification of activities and tools. 
The Game-based Learning is taken in a large sense, incorporating serious games, role games activities, gamification, simulations, etc.

Also, the Media-based Learning incorporates Videos, audios, videoconferencing, etc.

The Text-based Learning integrates any medium or tool which stresses on text as the main way for transferring information or knowledge.

Then, with the change of the dimensions of "mixing", we seek to provide the best learning experience conducive to raise the motivation and engagement of learners, especially since this variation is encouraged by the proliferation of new initiatives such as the Open Educational Resources (OER) in a globalized higher education context.

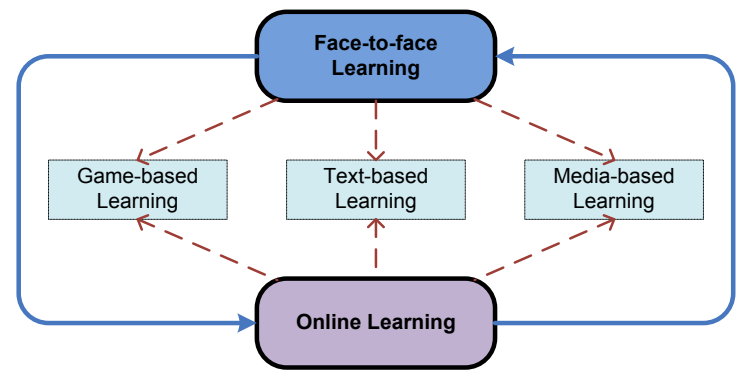

Figure 8. Levels of the blended learning

\section{2) Why the Multilevel-Blended Learning?}

In the context of developing countries, the issue of cost remains a major obstacle penalizing any development initiative. Thus, several factors intensify the limit in education:

- Budgetary and financial restrictions for content development and innovation processes.

- Constraints in terms of human resources and inadequacy or lack in competencies.

- Inability to face competition of the virtual world.

How can we counter this reality while maintaining quality and productivity in education?

As a response, the core of our approach relies essentially on an Integration-based Design of resources.

Stating that Knowledge and Content are everywhere, we have to demonstrate an "Intelligence of integration" to save time in developing contents and learning methods. A design based on the integration of existing supports, "Integration engineering", and clustering design is strongly proposed in our context.

We try, then, to reduce the gap with developed countries in terms of content and methods, assuring a psychological alignment of our students with developed references.

The reason for this integration logic comes from the development of several concepts related to open access to content and learning, strongly encouraged by new technology in general, and particularly the Internet. Concepts and initiatives like: Open Educational Resources (OER); Open Distance Learning (ODL); Open Access Initiatives (OAI); Massive Open Online Courses (MOOCs); Etc.
To illustrate this point, we'll give a brief description of those concepts, which are gaining more and more ground in the field of education and learning.

Open Access Initiatives (OAI): Open access Initiatives (OAI) provide free access to resources which can be available online and has fewer restrictions on their use [31], removing then price barriers and permission barriers.

Then, open and distance education have been increasingly important fields of intellectual excitement and innovative development. The challenges posed by the new technologies are permanent, and students constantly keep teachers under pressure to develop.

Open Educational Resources (OER): The OER has become a World Wide movement because Internet now opens a huge potential for education sector, including initiatives of Open Access to scientific information sources as well as the proliferation of Open Educational Resources (OER).

OERs are any type of educational materials and resources that are in the public domain or introduced with an open license [15]. They are offered freely and openly for anyone to use.

These initiatives allow, in a certain way, a psychological alignment with developed countries in terms of access to sources of information and educational resources. Thus, a kind of democratization of access to some knowledge, although the most relevant sources remain paid.

This can be a huge opportunity for developing countries [14], because of: the availability of contents; and the affordability and variety of choices made them suitable for institutions (according to their needs).

Massive Open Online Courses (MOOCs): MOOCs have become increasingly popular since they first emerged in 2008. Free and easily accessible, MOOCs offer to large numbers of students the opportunity to study high quality courses with international universities.

Whilst MOOCs don't always lead to formal qualifications, they allow students to gain invaluable knowledge to support their careers, or their own personal learning goals. Then, MOOCs can be used in the personal level, in which, the learner can build his Personal Learning Platform [4], as a way to enhance the intrinsic motivation to the formal curriculum.

\section{Micro Level: Gamified learning activity}

At the micro level of our approach, we hold the way of content design and activity design, by which we can enhance motivation and engagement during the Learning Process.

It represents the level in which we go from the overview of the Learning Platform to the specific layer of definition of didactic tools, learning activities, and communication tools, as illustrated in the figure 9.

Then, as a way to enhance motivation, we can use game mechanics and game dynamics during the learning experience. So, we stress on Gamification as a process for "gamifying" activities and tools. 


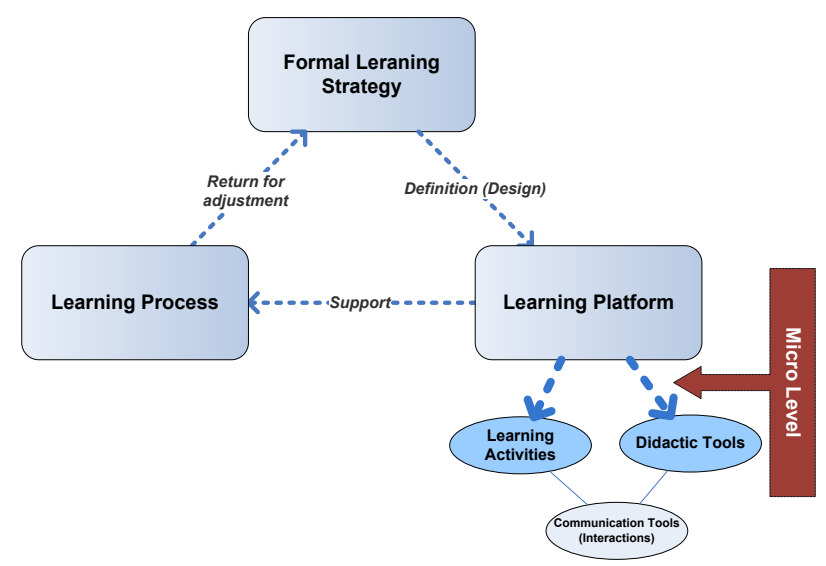

Figure 9. Micro Level

\section{1) Gamification: the characteristics}

Education is not necessarily associated with fun!, but, because there is novelty, a sense of accomplishment, and creativity by the possibility of applying what is learned, learning is more and more pleasurable [7].

Gamification is a rapidly growing, important, but young concept. The idea of using games mechanics and dynamics in serious contexts still shocks many people. And there isn't yet enough material about the promise and challenges of Gamification as an educational practice.

In our approach, Gamification is just about creating a learning opportunity with a different tool. At this configuration, we face a definition of new roles for the two important actors in learning context namely: the Instructor and the Learner.

For the Instructor, the roles of teacher migrate to three essential functions: role of "Moderator"; role of "Facilitator"; role of "Integrator" of content and learning platforms.

For the Learner, within a serious context, the learner of the $21^{\text {th }}$ century can enjoy the learning experience, mixing between Learning and Plying at the same time. All these issues of Learning through play drive an extension of the concept of "Learnplayer".

We propose then, a descriptive scenario of Gamification of learning activity, which we have simplified to these two actors (the instructor and the learner) in the figure 10.
The specification/configuration of this meta-scenario changes according to each learning task/activity.

\section{2) Why the Gamification?}

According to the context of high education or tertiary education in morocco, we can't ask all educators to become game designers. For this reason, we stress on Gamification as a way of use of game mechanics and game dynamics in educational context.

At the same time, using only serious games is limitative in term of content. A game can't integrate all the content we want to administrate to learners, due to several limitations:

- development costs;

- competencies;

- etc.

Then, the application of Gamification principles during learning activities is justified, and can enhance motivation and varying the modes of learning that we should experiment in our context.

\section{CONCLUSION}

Motivation and engagement of learners during formal curriculums are and still key issues which we must respond. Thus, designing a learning experience that combines an attractive design quality and effective achievement of learning is a challenge that few designers have managed to overcome. Do not sacrifice the aspect of attractiveness to the learning objectives, and vice versa, remains essential.

In our approach, ranging from macro to micro level, the focus remains the learner. With the perspective of providing the best learning experience conducive to raise the motivation and engagement of learners. All within the constraints related to the context of a developing country.

It should be acknowledged that there are some limitations to this study. Because we are in a stage of sharpening an approach, that should be experienced.

Then, we will try, in next steps, to apply the S2P Learning Model in the configuration of a learning curriculum. And validate by applying this curriculum in a learning context.

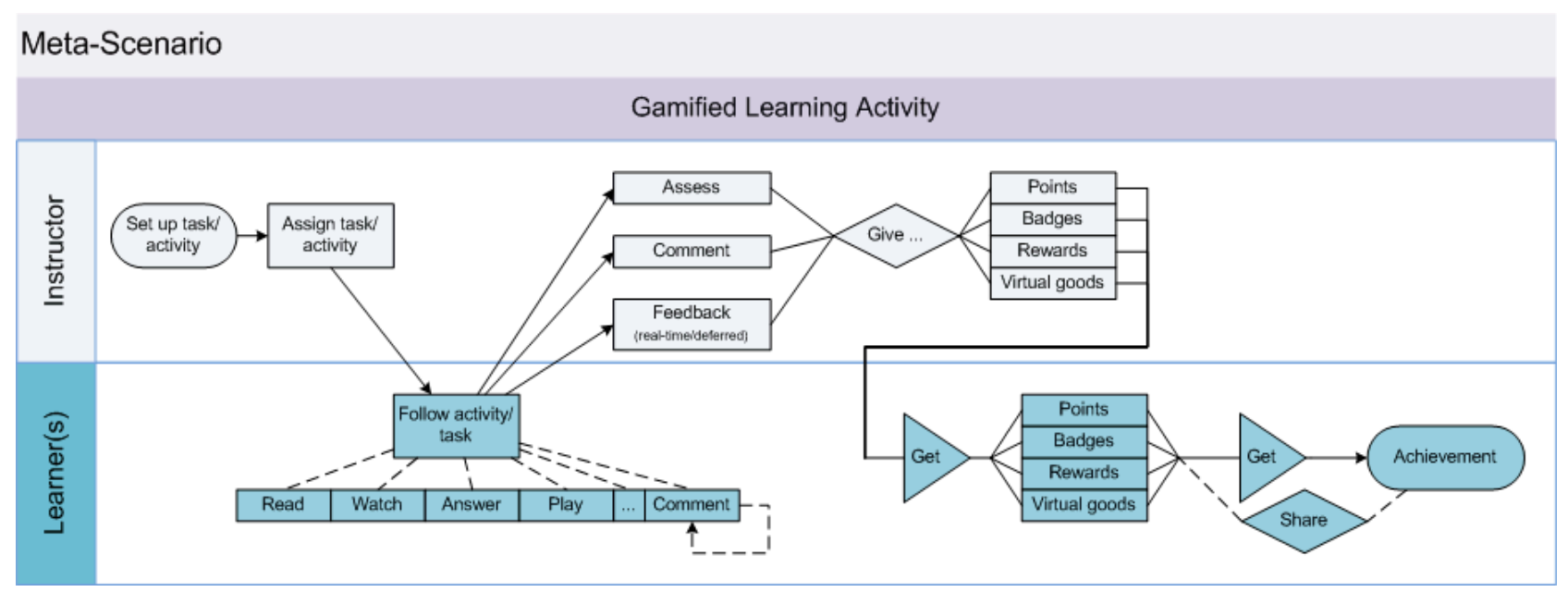

Figure 10. Simplified scenario of Gamification 


\section{REFERENCES}

[1] T. Amiel, "Identifying barriers to the remix of translated open educational resources," The International Review of Research in Open and Distance Learning, Vol. 14, No 1, 2013.

[2] E. Anderman, P.H. Winne, P.A. Alexander, L. Corno, "Handbook of educational psychology," New York, Routledge, $2^{\text {nd }}$ Edition, 2006.

[3] S.E. Bahji, Y. Lefdaoui, J. El Alami, "The Learning Model "S2P" as a Conceptual Framework for Understanding the "Serious Game," Proceedings of the $14^{\text {th }}$ IASTED International Conference "Computers and Advanced Technology in Education (CATE 2011)", Cambridge - United Kingdom, July 11 - 13, 2011.

[4] S.E. Bahji, Y. Lefdaoui, J. El Alami, "S2P Learning Model for combining Game-Based Learning and Text-Based Learning," Proceeding of the $5^{\text {th }}$ Guide International Conference 2011 "Elearning innovative models for the integration of education, technology and research", Rome - Italy November, 18-19 2011.

[5] S.E. Bahji, Y. Lefdaoui, J. El Alami, "The Learning Model S2P: a formal and a personal dimension," Proceeding of the $4^{\text {th }}$ International Conference on Next Generation Networks \& Services (NGNS'12), Algarve-Portugal, 2-4 December 2012.

[6] M.A. Blythe, K. Overbeeke, A.F. Monk, and P.C. Wright, "Funology: from usability to enjoyment," Kluwer Academic Publishers, Norwell, MA, 2004.

[7] J.E. Brophy, "Motivating Students to Learn," New York: Routledge, $3^{\text {rd }}$ Edition, 2010.

[8] M.V. Covington, "Goal Theory, Motivation and School Achievement: An Integrative Review," Annual Reviews of Psychology, No 51, 2000.

[9] S. Deterding, D. Dixon, R. Khaled, and L. Nacke, "From Game Design Elements to Gamefulness: Defining 'Gamification,', Proceeding of the MindTrek'11, Tampere, Finland, September 2830, 2011.

[10] S. Deterding, M. Sicart, L. Nacke, K. O'Hara, and D. Dixon, "Gamification. using game-design elements in non-gaming contexts," Proceedings of the 2011 annual conference on Human factors in computing systems (CHI EA '11), New York, USA, 2011.

[11] A. Domínguez, J. Saenz-de-Navarrete, L. de-Marcos, L. Fernández-Sanz, C. Pagés, J.J. Martínez-Herráiz, "Gamifying learning experiences: Practical implications and outcomes," Computer \& Education, No 63, 2013.

[12] Z. Dörnyei, "Teaching and researching motivation," Longman: Harlow, 2001.

[13] Z. Dörnyei, and E. Ushioda, "Teaching and Researching. Motivation," $2^{\text {nd }}$ edition, Longman, 2010.

[14] J. Egan, T. Frindt, , and J. Mbale, "Open Educational Resources and the Opportunities for Expanding Open and Distance Learning (OERS-ODL)," International Journal on Emerging Technologies in Learning (iJET), Vol. 8, Issue 2, May 2013.

[15] L. Ferrari, and I. Traina, "The OERTEST Project: Creating Political Conditions for Effective Exchange of OER in Higher Education," Journal of e-Learning and Knowledge Society, Vol.9, No. 1, January 2013.

[16] A. Glombitza, "A blended practice-enterprise course for language learning in an international business community," Journal of eLearning and Knowledge Society, Italian Edition, Vol.8, No 3, 2012.

[17] L. Juracz, "Developing Courses with HOLORENA, a Framework for Scenarie and Game-based e-Learning Environment," International Journal of Software Engineering \& Applications IJSEA, Vol.1, No.4, October 2010.

[18] J.J. Lee, and J. Hammer, "Gamification in Education: What, How, Why Bother?," Academic Exchange Quarterly, Vol.15, No 2, 2011.

[19] M.L Maehr, and H.A. Meyer, "Understanding motivation and schooling: Where we've been, where we are, and where we need to go," Educational Psychology Review, Vol. 9, No. 4, 1997. http://dx.doi.org/10.1023/A:1024750807365

[20] J. McGonigal, "Reality Is Broken: Why Games Make Us Better and How They Can Change the World," Penguin, London, 2011.

[21] B. Reeves, and J.L. Read, "Total Engagement: Using Games and Virtual Worlds to Change the Way People Work and Businesses Compete," Harvard Business School Press, Boston, MA, 2009.

[22] M. Romero, "Game-based Learning MOOC: Promoting Entrepreneurship Education," eLearning Papers, No 33, May 2013.

[23] K. Sadeghia, and M. Taghi Attar, "The relationship between learning strategy use and starting age of learning EFL," Procedia - Social and Behavioral Sciences, Vol. 70, 2013.

[24] B. Sbihi, "Towards a Mobile Education of the Sciences of Information in Morocco," International Journal of Emerging Technologies in Learning - iJET, Vol. 4, No 1, (2009).

[25] R.D. Steadward, E. J. Watkinson, and G.D. Wheeler, "Adapted physical activity," University of Alberta, 2003.

[26] J. Simões, R.D. Redondo, and A.F. Vilas, “A social gamification framework for a K-6 learning platform," Computers in Human Behavior, No 29, 2013.

[27] J. Uhomoibhi, and M. Ross, "E-Learning Development Trends in Computer and Engineering Education," International Journal of Engineering Pedagogy - iJEP, Vol. 3, Issue 2, April 2013.

[28] I. de-Waard, S. Abajian, M. Gallagher, R. Hogue, N. Keskin, A. Koutropoulos, and $\mathrm{O}$. Rodriguez, "Using mLearning and MOOCs to understand chaos, emergence, and complexity in education," The International Review Of Research In Open And Distance Learning, Vol 12, No 7, 2011.

[29] I. de-Waard, A. Koutropoulos, N.O. Keskin, S.C. Abajian, R. Hogue, C. Osvaldo Rodriguez, and M.S. Gallagher, "Exploring the MOOC format as a pedagogical approach for mLearning," Proceeding of the $10^{\text {th }}$ World Conference on Mobile and Contextual Learning. Beijing, China, 18-21 October 2011.

[30] M. Yadav, and H. BaniAta, "Factorizing Demotivation, Finding Motivation: A Constructive Approach to Quality Enhancement," Procedia - Social and Behavioral Sciences, Vol. 70, No 25, January 2013.

[31] K. Yiotis, "The Open Access Initiative: A New Paradigm for Scholarly Communications," Information Technology and Libraries, Vol. 24, No 4, 2005.

[32] G. Zichermann, and C. Cunningham, "Gamification by Design: Implementing Game Mechanics in Web and Mobile Apps," O'Reilly Media, Inc., First Edition, 2011.

\section{AUTHORS}

Salah Eddine BAHJI is with Laboratory of Systems Analysis, Information Processing and Integrated Management, Mohammed V Agdal University-Rabat, High School of Technology-Sale. Avenue Prince Heritier, B.P. $227 \quad$ Sale Medina, Morocco (SalahEddineBahji@research.ami.ac.ma).

Youssef LEFDAOUI, is with Mohammed V Agdal University-Rabat, High School of Technology-Sale. Avenue Prince Heritier, B.P. 227 Sale Medina, Morocco (ylefdaoui@gmail.com).

Jamila EL ALAMI is with Mohammed V Agdal University-Rabat, High School of Technology-Sale. Avenue Prince Heritier, B.P. 227 Sale Medina, Morocco. Pr. El Alami is the Head of the Laboratory of Systems Analysis, Information Processing and Integrated Management, Morocco, (alamijamila1@gmail.com).

Submitted 04 July 2013. Published as re-submitted by the authors 08 November 2013. 